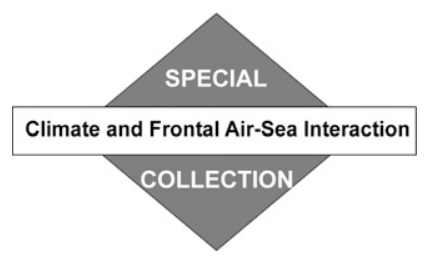

\title{
Role of the Cold Okhotsk Sea on the Climate of the North Pacific Subtropical High and Baiu Precipitation
}

\author{
Kenta Kawasaki, ${ }^{\mathrm{a}}$ Yoshiniro Tachibana, ${ }^{\mathrm{a}}$ Tetsu Nakamura, ${ }^{\mathrm{b}}$ And Koji Yamazaki ${ }^{\mathrm{c}}$ \\ ${ }^{a}$ Weather and Climate Dynamics Laboratory, Mie University, Mie, Japan \\ ${ }^{\mathrm{b}}$ Faculty of Environmental Earth Science, Hokkaido University, Hokkaido, Japan \\ ${ }^{\mathrm{c}}$ Arctic Research Center, Hokkaido University, Hokkaido, Japan
}

(Manuscript received 13 June 2020, in final form 2 October 2020)

\begin{abstract}
Summertime temperatures in marginal seas are, in general, colder than on the surrounding continent because of the large contrast in heat capacity between the land and the ocean. The Okhotsk Sea, which is covered by sea ice until early summer, is much colder than the surrounding continent in summer. The Okhotsk Sea is thus located in an area with one of the largest temperature contrasts of all the marginal seas in summertime midlatitudes. Cooled air over the Okhotsk Sea may have an impact on remote summer climates, such as by serving as the source of cold-air advection that results in a poor crop harvest in Japan. Here, we examine the role of the Okhotsk Sea on the early summer climate of the western part of the North Pacific through an ideal numerical experiment by artificially changing the model's default oceanic condition in the Okhotsk Sea to a condition of land cover. Simulation results reveal that the presence of the Okhotsk Sea increases precipitation of the baiu/mei-yu front through strengthening of the northward moisture flux at the western edge of an intensified North Pacific subtropical high. The Okhotsk influence farther extends toward western North America to which the strengthened jet stream with a storm track extends. This remote influence is achievable through feedback from a transient eddy anomaly that is activated by the surface temperature gradient between the cold Okhotsk Sea and the warm Pacific Ocean. The findings imply that the existence of the Okhotsk Sea strengthens the East Asian summer monsoons.
\end{abstract}

KEYWORDS: Atmosphere; Atmosphere-ocean interaction; Atmospheric circulation; Monsoons; Climatology; General circulation models

\section{Introduction}

The Okhotsk Sea, which lies in the coldest region of its latitudinal band in summer, plays an important role in the climate of the surrounding areas of Japan, the Russian Far East, and the Pacific Ocean. In fact, the summertime sea surface temperature (SST) is extremely low, as low as $5^{\circ} \mathrm{C}$ in some Okhotsk Sea cold spots (e.g., Tachibana et al. 2008; Tokinaga and Xie 2009; Nishikawa et al. 2014). These cold SSTs are lower than any reported summertime SSTs in other Northern Hemisphere seas at the same latitude (Fig. 1a). One reason for the cold summer SST is that the Okhotsk Sea is one of the southernmost ice-covered seas in the Northern Hemisphere in winter. Moreover, a strong oceanic tidal flow between the Okhotsk Sea and the North Pacific makes the Okhotsk Sea cool (e.g., Nakamura et al. 2000; Nishikawa et al. 2014) because the tidal flow combined with strong vertical mixing causes cold intermediate water to emerge from the sea surface. In contrast, summer temperatures over the continent facing the Okhotsk

¿ Denotes content that is immediately available upon publication as open access.

Corresponding author: Yoshihiro Tachibana, tachi@bio.mie-u.ac.jp
Sea are quite high owing to a typical subarctic climate along with long daylight hours. A stationary anticyclone, referred to as an Okhotsk high, occasionally appears over the cold Okhotsk Sea in the summer. Nakamura and Fukamachi (2004) and Tachibana et al. (2004) showed that the contrast in air temperature between the Okhotsk Sea and the surrounding continent plays a role in the formation of the Okhotsk high. The Okhotsk high is accompanied by cold fog (e.g., Tachibana et al. 2008), and cold SST with fog strengthens the Okhotsk high (Tokinaga and Xie 2009; Koseki et al. 2012; Nishikawa et al. 2014).

The Okhotsk Sea additionally affects remote climates. For example, winter sea ice variations in the Okhotsk Sea have influences on the strength of the Aleutian low (Honda et al. 1996, 1999) and the North Atlantic Oscillation (Yamamoto et al. 2006). The Okhotsk high has a remote impact on summer climates. For example, the high occasionally brings scant rice yield in Japan through southwestward cold-air advection from the area near the Kuril Islands located to the south of the Okhotsk Sea (e.g., Ogi et al. 2004). Ninomiya and Mizuno (1985) suggested a crucial role of the Okhotsk Sea in the formation of the baiu/mei-yu front, which is a stationary rainband that extends zonally from China to Japan and characterizes the early summer climate in Japan in association with the East Asian summer monsoon (e.g., Ninomiya and Shibagaki 2007). 

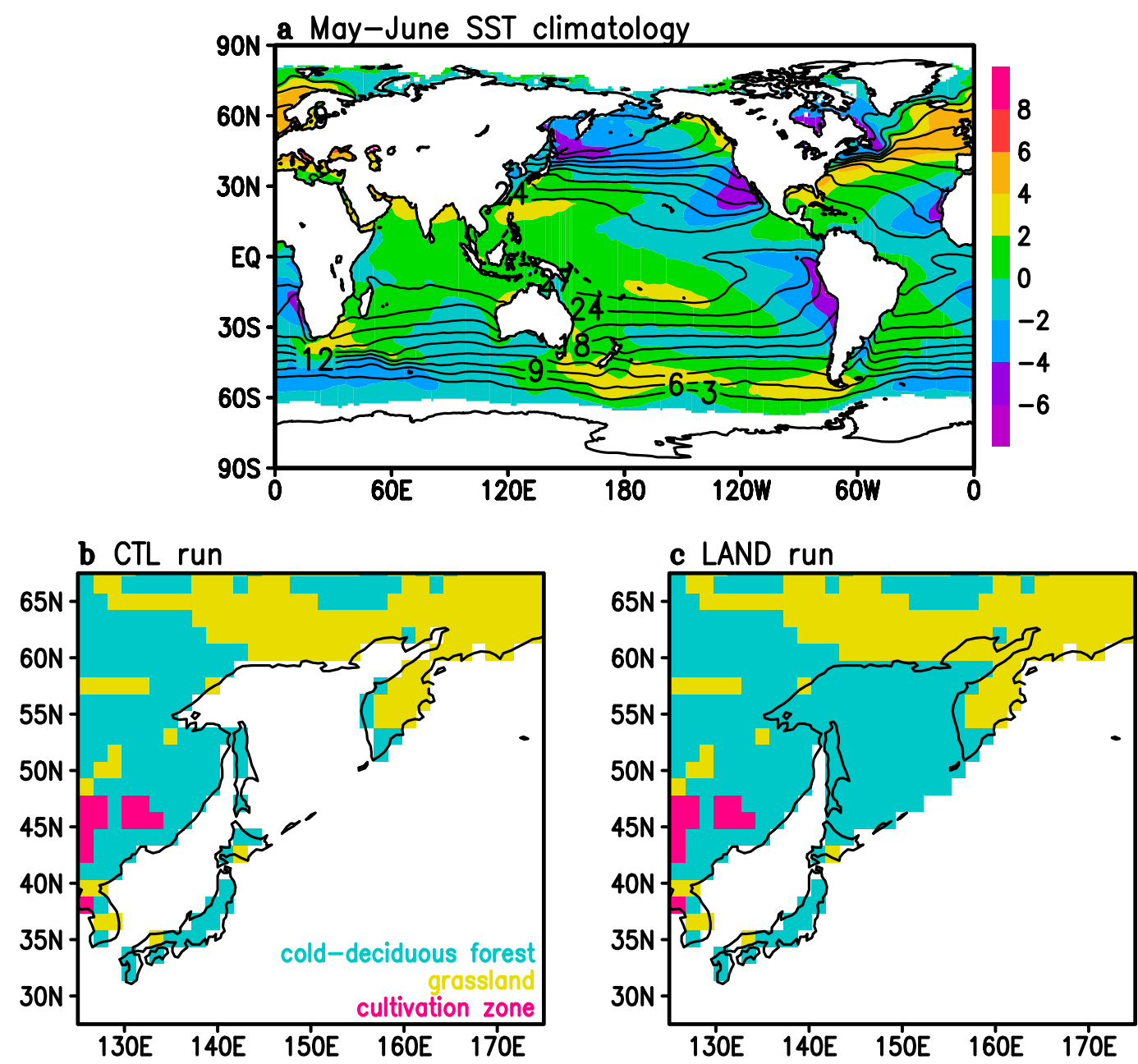

FIG. 1. (a) May-June SST climatology $\left({ }^{\circ} \mathrm{C}\right)$ of 1981-2010 period (contours) and its anomaly from zonal mean (color shading). Also shown are the ground parameters of the (b) control (CTL) and (c) LAND runs (blue: colddeciduous forest; yellow: grassland; red: cultivation zone).

baiu/mei-yu rainband activity is one of the most important climatic phenomena for the Japanese socioeconomy because moderate rainfall from the rainband supports agricultural crops like rice and mass consumption activities in Japan (e.g., Kanno 2013). Rainfall from the baiu rainband in association with the Okhotsk high occasionally causes catastrophic damage, such as occurred in 2018 in Japan in which an unprecedented baiu rainfall officially named "the heavy rain event of July 2018" resulted in 237 fatalities by floods. The floods completely destroyed 221 facilities and 6296 buildings (Moteki 2019; Shimpo et al. 2019; Cabinet Office, Japan 2019). Excessive baiu rainfalls thus damage the Japanese socioeconomy.

The formation of a stationary precipitation zone in association with the baiu/mei-yu front is known to be influenced by the existence of the warm Tibetan Plateau (e.g., Kitoh 2004; Sampe and Xie 2010). Conducting ideal atmospheric general circulation model (AGCM) experiments with and without Tibetan Plateau showed that the high altitudes of the Plateau play an essential role in the formation of the baiu/mei-yu front (Kitoh 2004). It is also widely understood that the Okhotsk Sea is deeply involved in the development of baiuassociated precipitation through strengthening of atmospheric disturbances interfused between the cold Okhotsk Sea and the warm Pacific Ocean (Ninomiya and Muraki 1986; Wang 1992).

These studies suggest the potential importance of the Okhotsk Sea for local and remote climates. Because the actual climate in an area is the result of complex interactions with many climatic subsystems, the contributions of the Okhotsk Sea and other subsystems are undistinguishable. To examine the role of the Okhotsk Sea, we consider how atmospheric circulation patterns would be changed locally and remotely if the Okhotsk Sea were replaced by a landmass. An ideal AGCM experiment is an excellent tool to answer this question. In the numerical model, the Okhotsk Sea can be changed to land as a lower boundary condition. This strategy is in the same manner as used by Kitoh (2004) in which simulation with/ without the Tibetan Plateau was conducted. Comparison of the 
AGCM conducted with and without the Okhotsk Sea can be used to isolate the importance of the Okhotsk Sea on local and remote climates. The purpose of the present study is to understand the role of the Okhotsk Sea by executing the two abovementioned AGCM runs targeting the early summer climate. It should be noted that the AGCM without the Okhotsk Sea does not aim to simulate actual climate conditions but is only utilized to more deeply understand the role of the Okhotsk Sea in the present climate. It should also be noted that identifying the cause of interannual variations in the atmospheric fields around the Okhotsk Sea is not an aim of this study.

\section{Data and methods}

\section{a. AGCM runs with and without the Okhotsk Sea}

We used the AGCM for Earth Simulator (AFES) (version 4.1; Ohfuchi et al. 2004, 2007; Enomoto et al. 2008; KuwanoYoshida et al. 2010) with the horizontal wavenumber being set to 79 (T79; approximately $1.5^{\circ}$ horizontal resolution) and the vertical levels set to 56 (model top is about $60 \mathrm{~km}$ ). We used the merged Hadley-National Oceanic and Atmospheric Administration (NOAA)/Optimum Interpolation Sea Surface Temperature (OISST) and sea ice concentration (SIC) (Hurrell et al. 2008) datasets as the boundary conditions to force the AGCM. The other conditions were the same as in the study of Nakamura et al. (2015). As the initial condition, we used the January 1979 monthly mean from the Japanese 25-year Reanalysis Project (JRA-25)/Japan Meteorological Agency (JMA) Climate Data Assimilation System (JCDAS) reanalysis data (Onogi et al. 2007).

A control (CTL) run was performed under the boundary condition of an annual cycle of the monthly mean SST and sea ice averaged over the period of 1979-83. Because recent drastic sea ice reduction in the Arctic sea ice might change the summer climate (e.g., Nakamura et al. 2019), we chose this former period as the baseline climate. A perturbed run (designated, LAND) was performed using the same boundary conditions as the CTL run except for boundary conditions over the Okhotsk Sea being changed from ocean to land as if the Okhotsk Sea was totally landfilled (Figs. 1b,c). The height of the ground in the Okhotsk area was set to the same height as sea surface level (i.e., $0 \mathrm{~m}$ ), and the ground conditions were changed to a cold-deciduous forest to match the conditions surrounding Siberia and Japan based on default land use types of this AGCM. We performed 30yr integrations after a 2-yr spinup, and the differences between the 30-yr averages of CTL and LAND runs (CTL minus LAND) were examined. We focused on the baiu/mei-yu front during its active period and thus data were averaged over the months of May and June. The baiu/mei-yu are active in July at least in midlatitude East Asia. The description of July is in the last section.

\section{b. Reanalysis data}

We used the Japan Meteorological Agency 55-year Reanalysis (JRA-55) data (Harada et al. 2016) and Hadley Centre Sea Ice and Sea Surface Temperature (HadISST) (Rayner et al. 2003) datasets to examine whether the simulation results based on unrealistic and drastic changes to the Okhotsk Sea were supported by observation data. We used these reanalysis data for the period of 1958-2012. Both datasets were averaged over the months of May and June. May-June SST climatology and its anomaly from its zonal mean shown in Fig. 1a are also from HadISST.

\section{c. Methods}

To examine changes in the atmospheric conditions that affect synoptic disturbances, we calculated the absolute value of the horizontal temperature gradient defined as

$$
|\nabla T|=\sqrt{\left(\frac{\partial T}{\partial x}\right)^{2}+\left(\frac{\partial T}{\partial y}\right)^{2}},
$$

where $T$ is temperature and $x / y$ is the distance along longitude/ latitude.

We also used the maximum Eady growth rate (Eady 1949), which expresses the development of the baroclinic unstable wave, defined as

$$
\sigma_{\text {max }}=0.31 \frac{f}{N H} \delta U,
$$

where $f$ is Coriolis parameter, $N$ is Brunt-Väisälä frequency, $H$ is height difference from 850 to $300 \mathrm{hPa}$, and $\delta U$ is zonal wind shear between 850 and $300 \mathrm{hPa}$.

The storm-track intensity is defined as the variance of the high-frequency meridional wind variation at the $300-\mathrm{hPa}$ level, as expressed by Eq. (3) as

$$
\text { Storm track }=\overline{v^{\prime} v^{\prime}},
$$

where the overbar indicates monthly mean, $v$ denotes daily mean meridional wind speed, and the prime indicates departure from 7-day moving average.

We used the E-vector (Hoskins et al. 1983), which is a useful tool for diagnosing the effect of eddy momentum transport to accelerate/decelerate mean flow. The divergence of the E-vector corresponds to the acceleration of mean flow. The E-vector is defined as

$$
\mathbf{E}=\left(\overline{v^{\prime} v^{\prime}}-\overline{u^{\prime} u^{\prime}},-\overline{u^{\prime} v^{\prime}}\right)
$$

where $v$ is meridional wind, $u$ is zonal wind, and the prime indicates departure from 7-day moving average.

We further use a quasigeostrophic potential vorticity (QGPV) method to examine the feedback of transient eddy activity on the mean flow (e.g., Fang and Yang 2016). QGPV framework is a useful method to diagnose the geopotential tendency due to the diabatic and the transient eddy forcing. We applied the QGPV diagnosis to the simulated anomalies of CNTL minus LAND runs. Using the geopotential tendency equation,

$$
\begin{aligned}
\left(\frac{1}{f} \nabla^{2}+\frac{f}{\sigma} \frac{\partial^{2}}{\partial p^{2}}\right)\left(\frac{\partial \Delta \Phi}{\partial t}\right)= & -f \frac{\partial}{\partial p}\left(\frac{\alpha}{\sigma} \frac{\Delta Q_{\text {diab }}}{T}\right) \\
& -f \frac{\partial}{\partial p}\left(\frac{\alpha}{\sigma} \frac{\Delta Q_{\text {eddy }}}{T}\right) \\
& +\Delta F_{\text {eddy }}+\text { Res }
\end{aligned}
$$

where $\Phi$ is the geopotential, $p$ is the pressure, $\alpha$ is the specific volume, $\sigma$ is the static stability parameter, and Res is a residual 

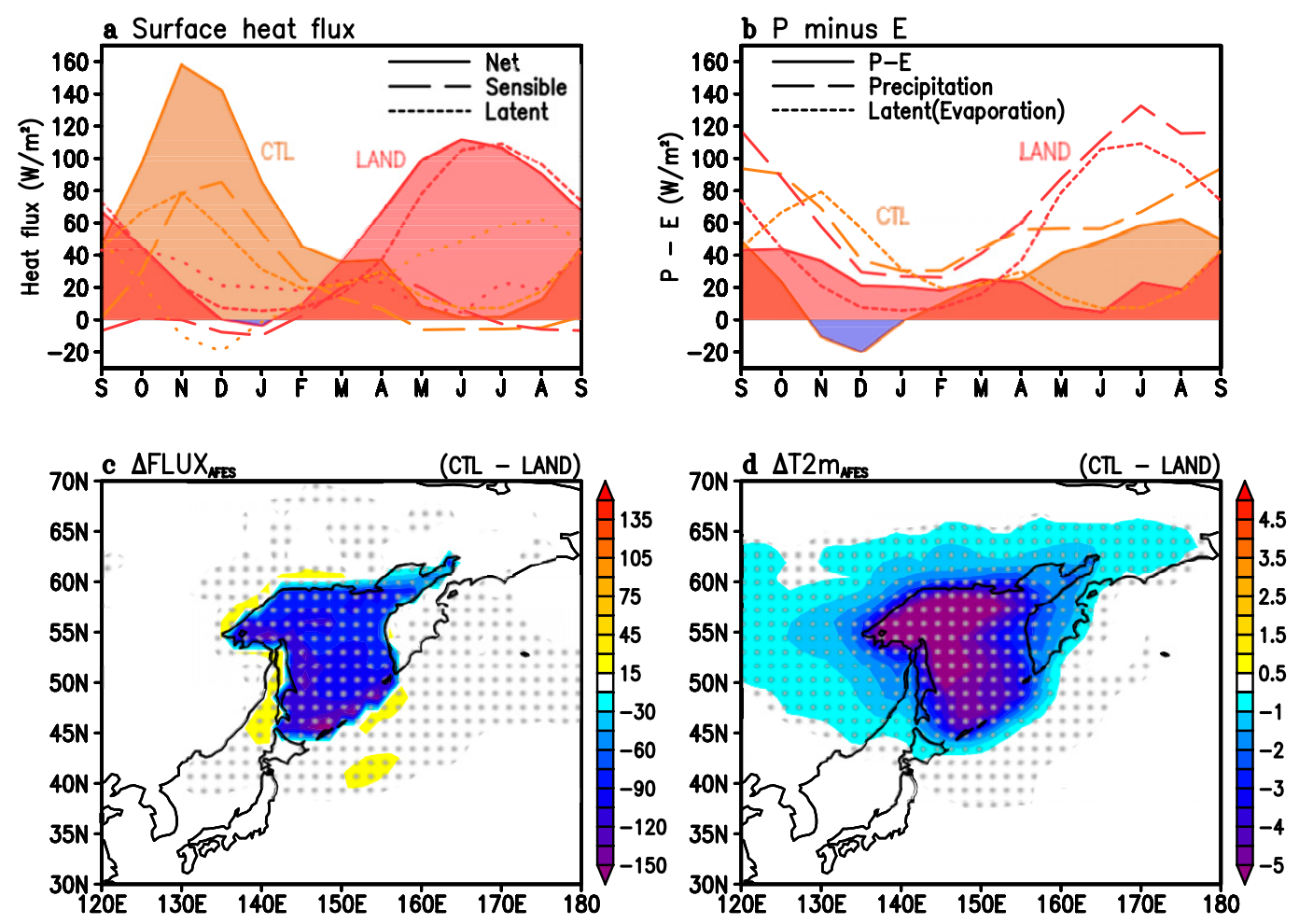

FIG. 2. (a) Mean annual cycle of the sensible (dashed line), latent (dotted line), and their total (solid line) heat flux $\left(\mathrm{W} \mathrm{m}^{-2}\right)$ averaged over the Okhotsk Sea. Orange and red colors indicate the fluxes of the CTL and LAND runs, respectively. Positive value denotes heat transport from the surface to the atmosphere. (b) As in (a), but for precipitation (dashed line), precipitation minus evaporation (i.e., $P-E$; solid line), and latent heat flux(dotted line). Also shown are the difference in May-June (c) mean total heat flux $\left(\mathrm{W} \mathrm{m}^{-2}\right)$ and (d) mean temperature at $2 \mathrm{~m}$ $\left({ }^{\circ} \mathrm{C}\right)$ between the CTL and LAND runs (CTL minus LAND). Hatching indicates significance level above $95 \%$ based on a $t$ test.

term, all based on monthly mean $3 \mathrm{D}$ fields. The $\Delta$ indicates anomaly of CNTL minus LAND runs; $Q_{\text {diab }}$ is the diabatic heating, which the model directly calculated. In Eq. (5), $Q_{\text {eddy }}$ and $F_{\text {eddy }}$ are eddy heat flux convergence and eddy vorticity flux convergence, respectively, defined as

$$
\begin{aligned}
Q_{\text {eddy }} & =-\nabla \cdot \overline{\mathbf{V}_{g}^{\prime} T^{\prime}}-\frac{\partial \overline{\omega^{\prime} T^{\prime}}}{\partial p}+\frac{R}{c_{p} p} \overline{\omega^{\prime} T^{\prime}} \text { and } \\
F_{\text {eddy }} & =-\nabla \cdot \overline{\mathbf{V}_{g}^{\prime} \zeta^{\prime}},
\end{aligned}
$$

where $\mathbf{V}_{g}$ is the geostrophic wind vector, $\omega$ is the pressure velocity, $\zeta$ is the relative vorticity, and $R$ and $c_{p}$ are gas constant and specific heat at constant pressure, respectively. The overbar indicates 7-day moving average, and the prime indicates departure from 7-day moving average.

Vertically integrated moisture flux is used to determine whether the baiu rainband is intensified by circulation anomalies. Moisture flux convergence is defined as

moisture flux convergence $=-\left(\frac{1}{g} \int_{500}^{925} \frac{\partial u q}{\partial x} d P+\frac{1}{g} \int_{500}^{925} \frac{\partial v q}{\partial y} d P\right)$, where $g$ is acceleration of gravity, $u$ is zonal wind, $v$ is meridional wind, $P$ is pressure, and $q$ is moisture mixing ratio (i.e., specific humidity).

\section{Results}

\section{a. Model results}

First, we describe the characteristics of heat and moisture exchanges between the surface and the overlying atmosphere in the Okhotsk region. Figures $2 \mathrm{a}$ and $2 \mathrm{~b}$ show the annual cycle of the area-averaged upward net heat fluxes on the surface of the Okhotsk Sea (the area average is based on grids of the altered surface conditions as shown in Figs. $1 \mathrm{~b}$ and 1c). The effect of atmospheric heating through sensible and latent heat transport from the sea surface in the CTL run is low in the summer season but reaches a maximum in the winter season. In contrast, the seasonal evolution of atmospheric heating in the LAND run shows a near reversal of that in the CTL run. Large latent heat transport associated with large precipitation mainly contributes to large atmospheric heating in the LAND run. Sensible heat flux is also larger in the LAND run than in the CTL run, but it is secondary. These results signify that the Okhotsk Sea inhibits heat transport from the surface in summer. The 

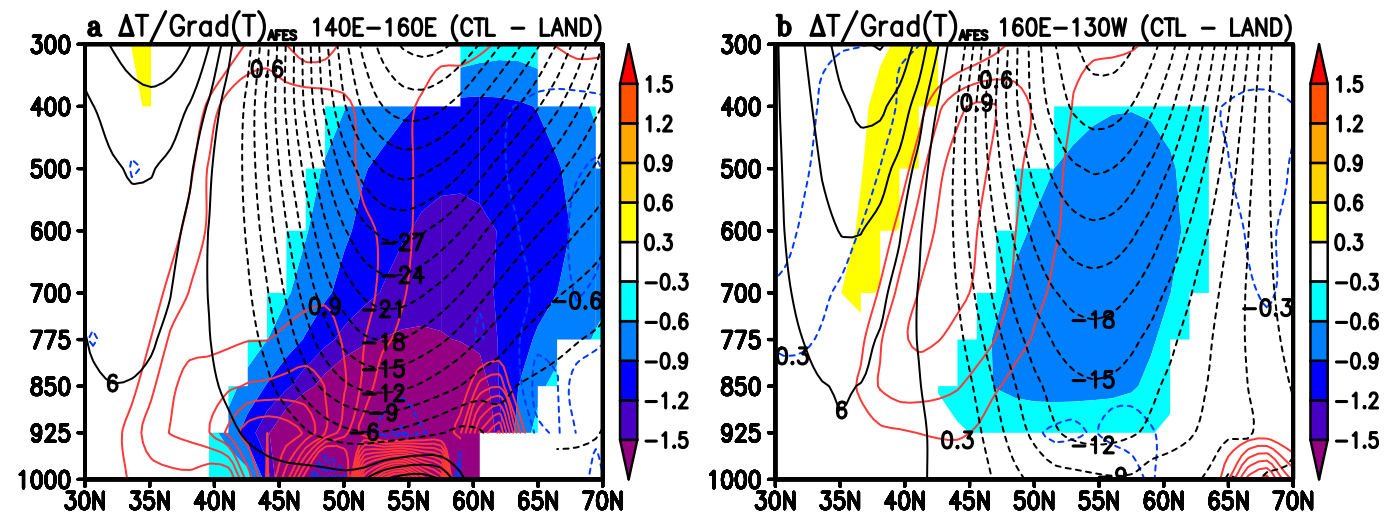

FIG. 3. Zonal cross sections of (a) $140^{\circ}-160^{\circ} \mathrm{E}$ and (b) $160^{\circ} \mathrm{E}-130^{\circ} \mathrm{W}$ average differences between the CTL and LAND runs (CTL minus LAND). Color shading indicates May-June mean temperature $\left({ }^{\circ} \mathrm{C}\right.$ ) (only significance levels above $95 \%$ are shaded $)$, and red/blue contours indicate temperature gradient $\left[{ }^{\circ} \mathrm{C}(100 \mathrm{~km})^{-1}\right]$. A positive sign of the gradient here denotes that the poleward temperature decline is larger in CTL than in LAND. Black contours indicate geopotential height $(\mathrm{m})$ difference of CTL minus LAND.

comparison of CTL with LAND results, thus, represents the atmospheric response to an anomalous cooling effect due to the presence of the Okhotsk Sea. Figure 2c shows the MayJune (MJ) mean net heat flux difference between the CTL and LAND runs (CTL minus LAND). Strong negative anomalies over the Okhotsk Sea are caused by the presence of the cold sea; that is, the Okhotsk Sea functions as a cold source. Figure $2 d$ shows the $2 \mathrm{~m}$ temperature anomalies of the CTL run from the LAND run. Negative anomalies centered on the Okhotsk Sea are observed and correspond to anomalous cooling forcing over it. The CTL run shows surface temperature fields are about $6^{\circ} \mathrm{C}$ lower than that in the LAND run.

Next, we examined the impact of the cold surface temperature over the Okhotsk Sea on the middle troposphere over the

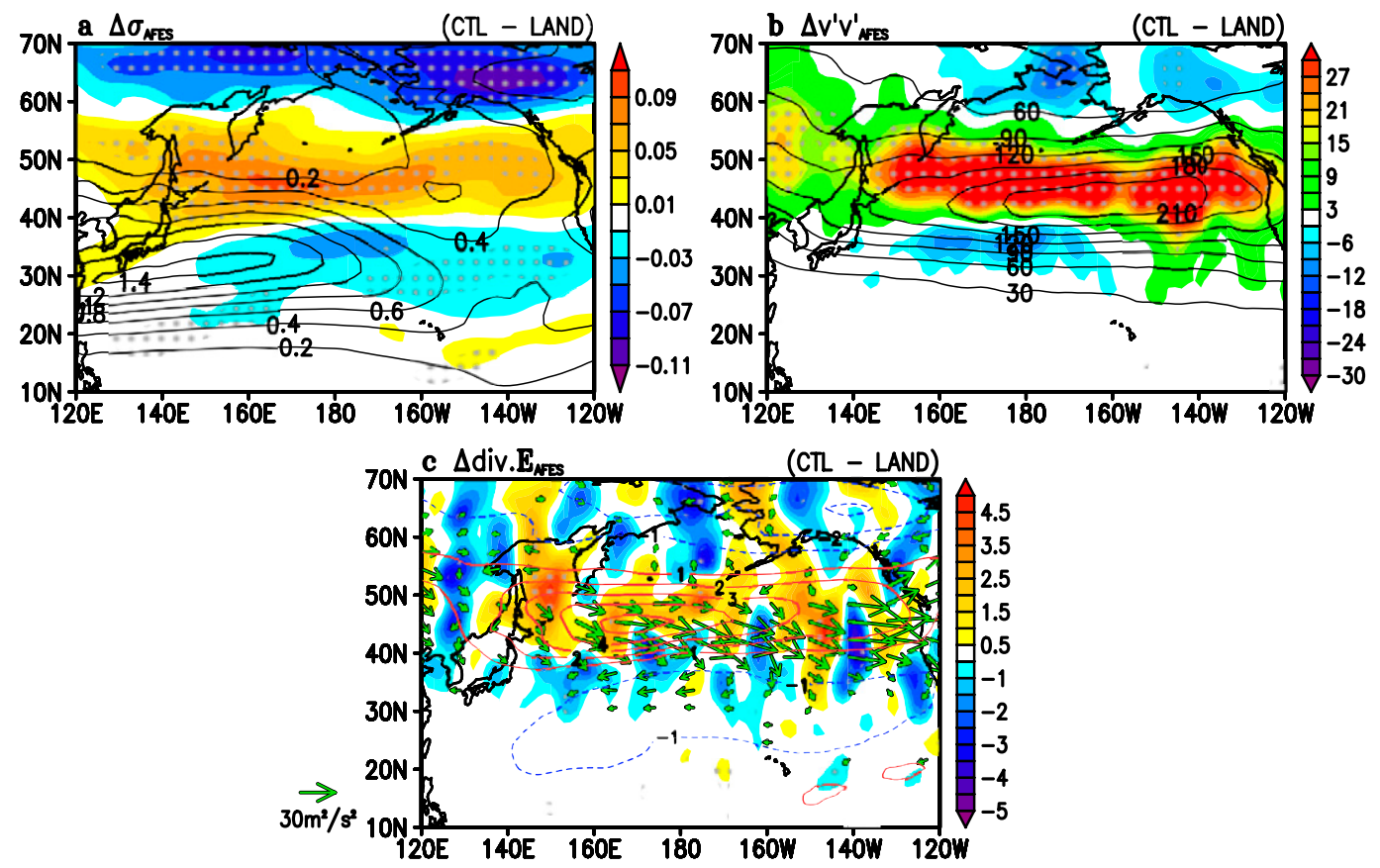

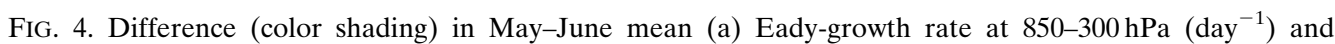
(b) storm-track intensity at $300 \mathrm{hPa}\left(\mathrm{m}^{2} \mathrm{~s}^{-2}\right)$ between the CTL and LAND runs (CTL minus LAND). Contours in (a) and (b) indicate climatological mean of Eady growth rate and the storm-track intensity, respectively, in the CTL run. Hatching indicates significance level above $95 \%$ based on a $t$ test. (c) Difference in divergence of E-vector at $300 \mathrm{hPa}\left(10^{-4} \mathrm{~m} \mathrm{~s}^{-2}\right)$ between the CTL and LAND runs. Arrows and contours indicate difference in E-vector at $300 \mathrm{hPa}\left(\mathrm{m}^{2} \mathrm{~s}^{-2}\right)$ and zonal wind at $300 \mathrm{hPa}\left(\mathrm{m} \mathrm{s}^{-1}\right)$, respectively. 

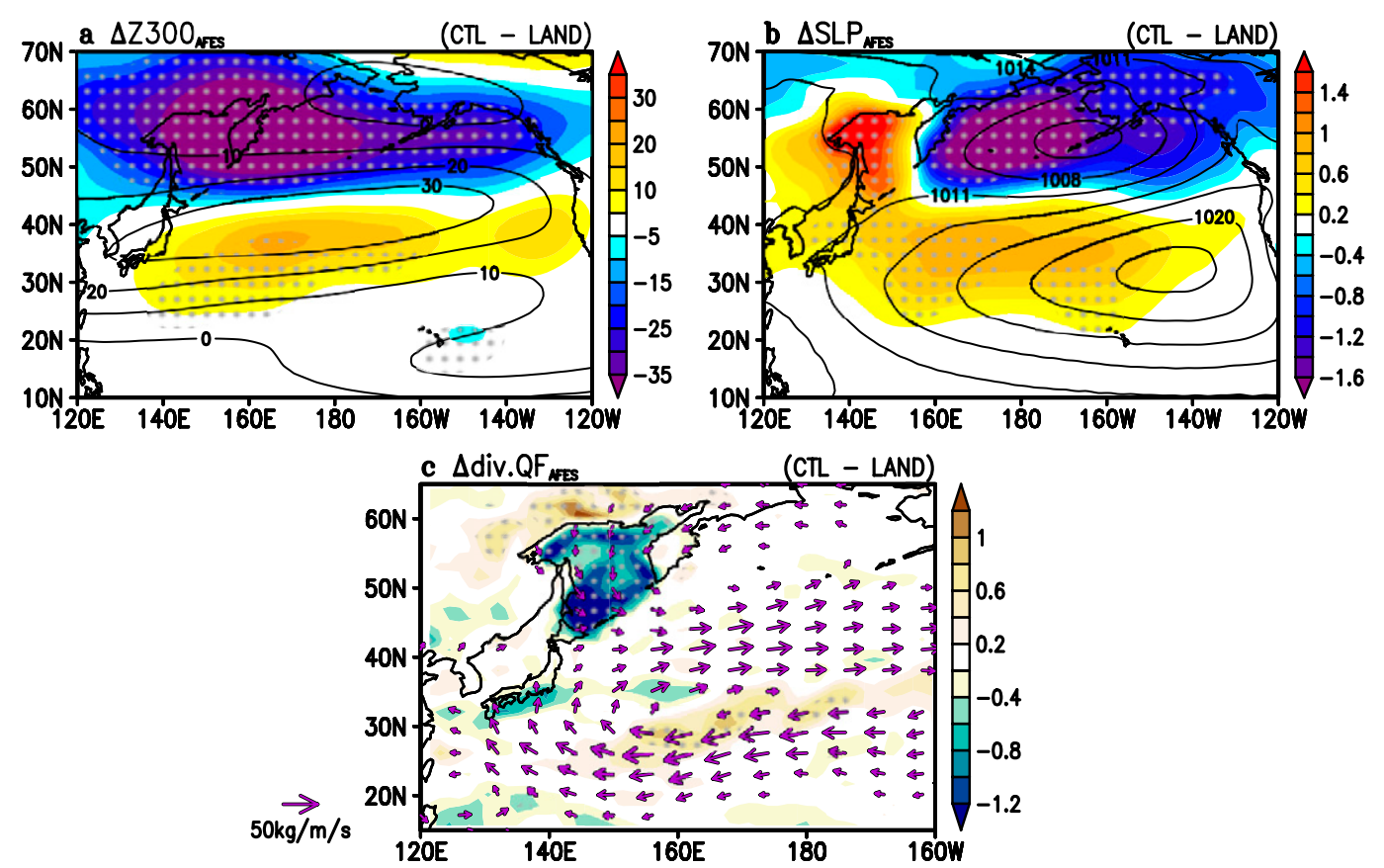

FIG. 5. Color shading shows the difference in May-June mean (a) geopotential height at $300 \mathrm{hPa}(\mathrm{m})$ and (b) sea level pressure (hPa) between the CTL and LAND runs (CTL minus LAND). Hatching indicates significance levels above $95 \%$ based on a $t$ test. Contours in (a) and (b) indicate climatological means of the zonal wind at $300 \mathrm{hPa}$ $\left(\mathrm{m} \mathrm{s}^{-1}\right)$ and sea level pressure $(\mathrm{hPa})$, respectively, defined as the 30 -yr average of the CTL run. (c) Difference in vertically integrated moisture flux (arrows) and its divergence (color shading) at $950-500 \mathrm{hPa}\left(\mathrm{mm} \mathrm{day}^{-1}\right.$ ) between the CTL and LAND runs. Hatching indicates significance level above $95 \%$ based on a $t$ test. Arrow length corresponding to $50 \mathrm{~kg} \mathrm{~m}^{-1} \mathrm{~s}^{-1}\left(=50 \mathrm{~mm} \mathrm{~m} \mathrm{~s}^{-1}\right)$ is indicated to the left of the panel.

North Pacific Ocean. Figure 3 shows the meridional cross section of temperature differences between the CTL and LAND runs based on the $140^{\circ}-160^{\circ} \mathrm{E}$ and $160^{\circ}-130^{\circ} \mathrm{W}$ averages, which range from the western North Pacific to the eastern North Pacific. The cold surface over the Okhotsk Sea in the CTL strengthens atmospheric vertical stratification over the Okhotsk Sea (Fig. 3a, color shading). Cold anomalies centered over the latitudes of the Okhotsk Sea vertically extend to the upper level atmosphere with northward tilting. Geopotential height also tilts northward (Fig. 3a, black contours). The vertical structure is thus baroclinic. A strong poleward temperature decline centered in the southern edge of the Okhotsk Sea is seen (Fig. 3a, contours). The cold anomalies extend to the downstream side of the westerlies (Fig. 3b) along with the extension of the strong poleward temperature decline. Consequently, a band of stronger poleward temperature decline is found from $40^{\circ}$ to $50^{\circ} \mathrm{N}$ over the North Pacific Ocean. The contours of geopotential height signify equivalent barotropic structure and strong westerly winds in the latitudes of the strong temperature decline owing to thermal wind balance. In addition, strengthened temperature decline is an indication of a state being baroclinically less stable. Thus, the Eady growth rate, which is an indication of the development of baroclinic instability, is largely altered by the effect of the cold Okhotsk Sea. An anomalously high development area of baroclinic unstable waves is located at the latitudinal band of $40^{\circ}-$ $55^{\circ} \mathrm{N}$ and extends zonally from the Okhotsk Sea to western
North America (Fig. 4a), and this area approximately corresponds to the area of strengthening poleward temperature decline due to the presence of the cold Okhotsk Sea (Fig. 3). A band showing weakened baroclinicity around $60^{\circ}-70^{\circ} \mathrm{N}$ corresponds to weakening of the temperature gradient and its associated weak westerlies between the midlatitudes and the Arctic.

Formation of a zone of strengthened baroclinic unstable waves results in a traveling path of synoptic disturbances. Figure $4 \mathrm{~b}$ shows the storm-track anomalies of CTL from the LAND runs. Positive anomalies are located at $40^{\circ}-50^{\circ} \mathrm{N}$, which correspond to the development area of the baroclinic unstable waves, whereas negative anomalies can be observed from $55^{\circ} \mathrm{N}$ to more northern latitudes. The positive anomaly zone is in agreement with that of a climatological storm track (Fig. 4b, contours). These results imply that presence of the cold Okhotsk Sea strengthens the activity of climatological synoptic disturbances, and this effect extends downstream toward western North America along the latitude band of $40^{\circ}-50^{\circ} \mathrm{N}$. Climatological influence of the Okhotsk Sea is thus beyond the Pacific Ocean.

It is a common knowledge that this latitude band is an area with a climatologically strong jet stream. The jet stream has a dynamically deep relationship to synoptic-scale eddies, as the interaction between the eddy and mean flow has been investigated in many studies. For example, storm-track activity has an upscale impact on the mean steady fields, and this upscale 

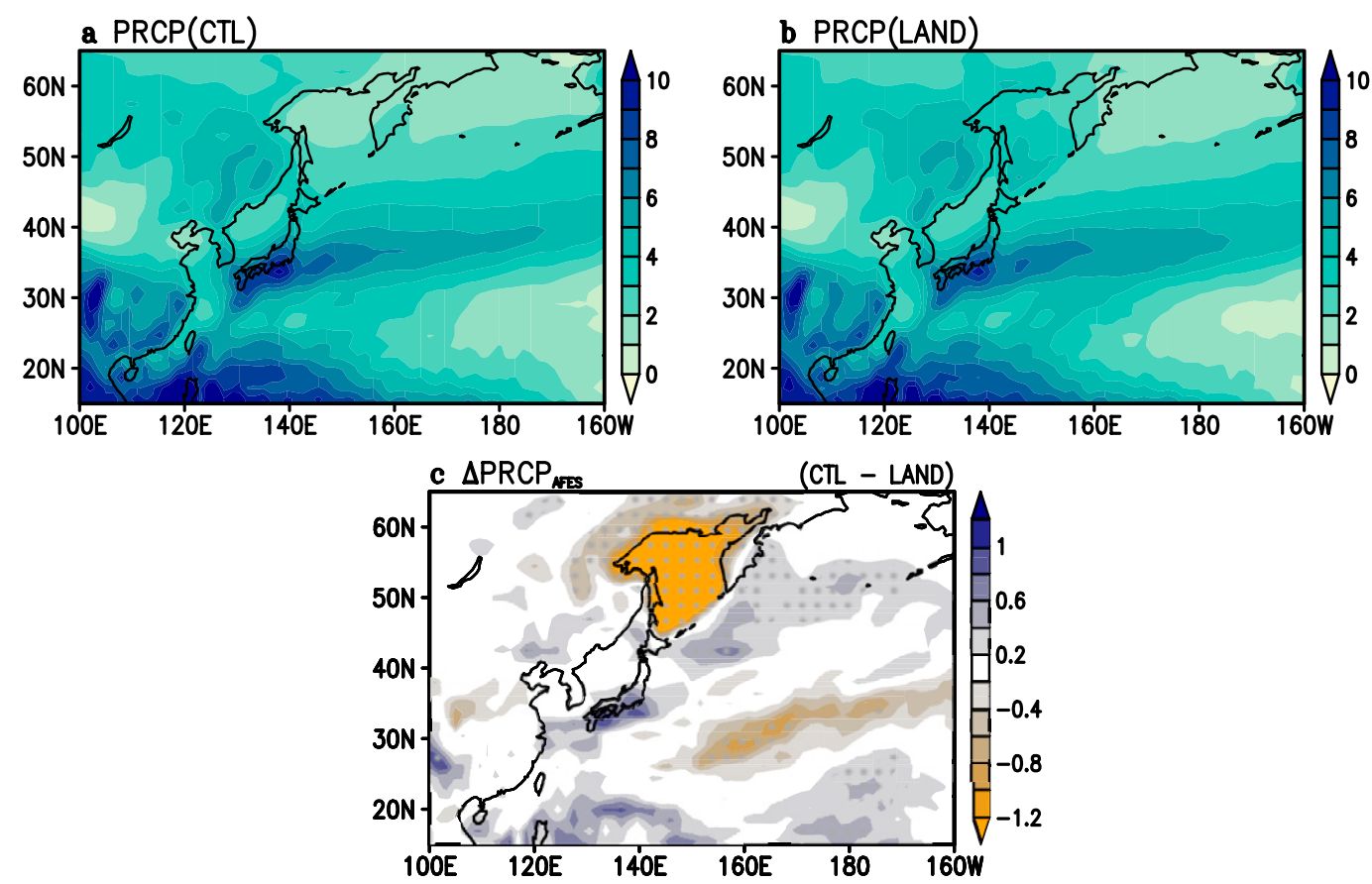

FIG. 6. Climatology of May-June mean precipitation $\left(\mathrm{mm} \mathrm{day}^{-1}\right)$ in the (a) CTL and (b) LAND runs. (c) Difference in precipitation $\left(\mathrm{mm} \mathrm{day}^{-1}\right)$ between the CTL and LAND runs (CTL minus LAND). Hatching indicates significance level above $95 \%$ based on a $t$ test.

impact is important for maintaining the jet stream (Lau and Nath, 1991). Based on this, we examined the relationship between the jet stream and the anomalous development of the synoptic disturbances caused by the effect of the cold Okhotsk Sea. Figure $4 c$ shows CTL-minus-LAND differences in the E-vector, its divergence, and zonal wind at the $300 \mathrm{hPa}$ level. Positive anomalies of divergence of the E-vector are observed in a latitudinal band from $40^{\circ}$ to $50^{\circ} \mathrm{N}$, which corresponds well with the spreading directions of the anomalous E-vectors. Additionally, westerly wind anomalies also appear at the same locations, suggesting that strengthened disturbance caused by the cold Okhotsk Sea forces an acceleration of the mean westerly flow, which in turn is accompanied by positive and negative vorticity anomalies to the north and south, respectively. We next examined changes in pressure fields in the midlatitude troposphere produced by the presence of the cold Okhotsk Sea.

Figure 5a shows anomalies of the geopotential height at $300 \mathrm{hPa}$ between the CTL and LAND runs. Cyclonic/ anticyclonic anomalies are located north/south of the accelerated jet stream that is centered around $45^{\circ} \mathrm{N}$. The maximal zone of climatological mean zonal wind (Fig. 5a, contours) agrees closely with that of an acceleration of the mean westerly flow (Fig. 4c). An eddy-induced anomalous vorticity field at the upper level induces circulation anomalies at the surface level. Figure 5b shows anomalies in sea level pressure. Positive anomalies located over the Pacific are similar to the upper positive height anomalies and correspond to intensification of the subtropical anticyclone, i.e., the North Pacific subtropical high. Thus, the anomalies over the Pacific region show the barotropic structure. In contrast, the anomalies over the Okhotsk Sea show the baroclinic structure, in which positive anomalies are found in the sea level pressure, whereas negative height anomalies are found at the upper level. This strong baroclinic structure is consistent with formation of the surface Okhotsk high, which has a shallow high pressure system induced by cold surface conditions over the Okhotsk Sea (Tachibana et al. 2004).

Here, we focus on the strengthened North Pacific subtropical high because moisture transport along the western edge of the Pacific high is an important factor in early summer precipitation over Japan. Using this, we next calculate convergence of moisture flux brought by the presence of the cold Okhotsk Sea. Figure 5c shows anomalies of vertically integrated moisture flux and its convergence. While convergence anomalies are seen over Japan, divergence anomalies are seen in the central Pacific, indicating the increase of moisture transport into Japan from the warm and moist area on the western edge of the strengthened North Pacific subtropical high. We can easily suppose that this moisture flux convergence induces an increase in precipitation over Japan. Figures $6 \mathrm{a}$ and $6 \mathrm{~b}$ show climatological precipitation patterns in the CTL and LAND runs, respectively. The stationary precipitation band corresponding to the baiu front is present over the southern part of Japan in both runs. Thus, we cannot say that the presence of the cold Okhotsk Sea is a necessary condition for the formation of climatological baiu-precipitation. However, precipitation differences between the CTL and LAND runs show positive anomalies over Japan and intensification of the climatological precipitation pattern (Fig. 6c), suggesting the possible 

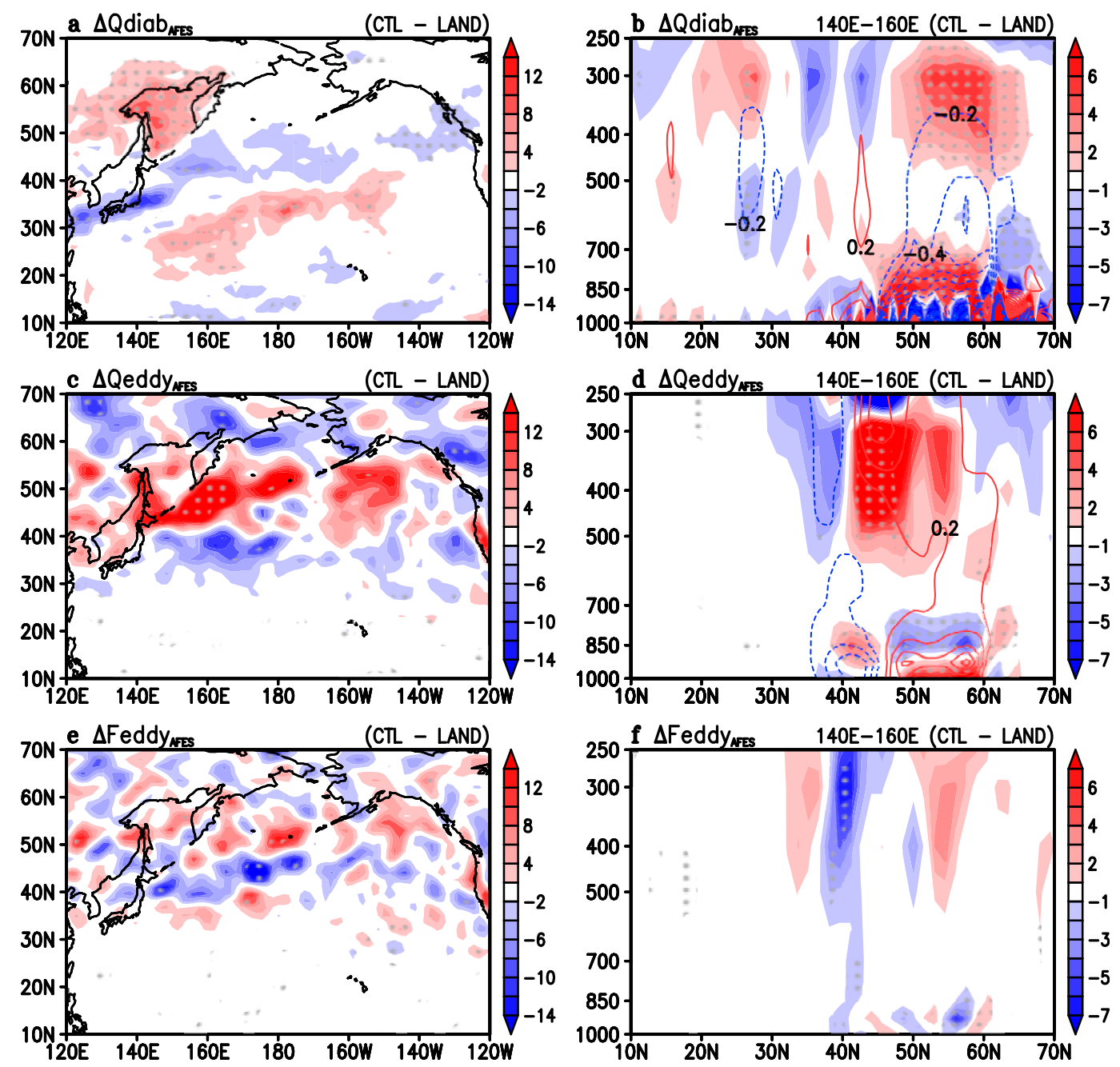

FIG. 7. May-June average diabatic heating-induced PV forcing anomaly $\left(10^{-6} \mathrm{~s}^{-1}\right.$ day $\left.^{-1}\right)$ (CTL minus LAND) (a) at $300 \mathrm{hPa}$ and (b) its meridional cross section averaged over $140^{\circ}-160^{\circ} \mathrm{E}$. Red and blue colors correspond to positive (cyclonic) and negative (anticyclonic) PV forcing anomalies, respectively. Hatching indicates significance level above $95 \%$ based on a $t$ test. Similar panels are drawn for PV forcing anomaly due to (c),(d) eddy heat flux convergence and (e),(f) eddy vorticity flux convergence. Contours in (b) and (d) indicate diabatic heating and eddy heat flux convergence anomalies $\left(\mathrm{K} \mathrm{day}^{-1}\right)$, respectively.

influence of the Okhotsk Sea on the strengthening of the baiuprecipitation band. The increase rate of precipitation in the southern part of Japan is about $10 \%$.

Interestingly, significant negative anomalies in precipitation were found over the Okhotsk Sea. The underlying cold ocean produces a static stable atmosphere with large stratification that possibly weakens atmospheric convective clouds and rainfall. Large atmospheric stratification in the atmospheric boundary layer also suppresses surface evaporation. The strengthened Okhotsk high due to the cold sea may also suppress overlying convections. In fact, direct radiosonde measurement showed that surface temperature was $10^{\circ} \mathrm{C}$ colder than that at the height of $500 \mathrm{~m}$ over the Okhotsk Sea (See Fig. 8 in Nishikawa et al. 2014). To the contrary, high surface temperature in the LAND run activates convective clouds and rainfall more than in the CTL run. This is in agreement with surface heat flux (See
Fig. 2). Large latent heat transport associated with large precipitation mainly contributes to large atmospheric heating in the LAND run.

\section{b. Quasigeostrophic potential vorticity (QGPV) diagnosis}

The role of feedback from transient eddies is usually discussed with comparison against the role of the diabatic heating (e.g., Fang and Yang 2016; Wang et al. 2017; Tao et al. 2020). Here we evaluate both of the eddy feedback process and the diabatic process due to the strong surface cooling anomaly in the Okhotsk Sea by using the QGPV diagnosis shown in Eqs. (5)-(7). Positive potential vorticity (PV) (i.e., cyclonic) forcing anomaly due to the diabatic heating is obvious over the Okhotsk Sea (Fig. 7a). This PV forcing is seen in upper tropospheric levels over the Okhotsk Sea (Fig. 7b). A negative PV forcing anomaly is also found over Japan corresponding to the 
a $\Delta Z 300$ tendency due to Qdiab
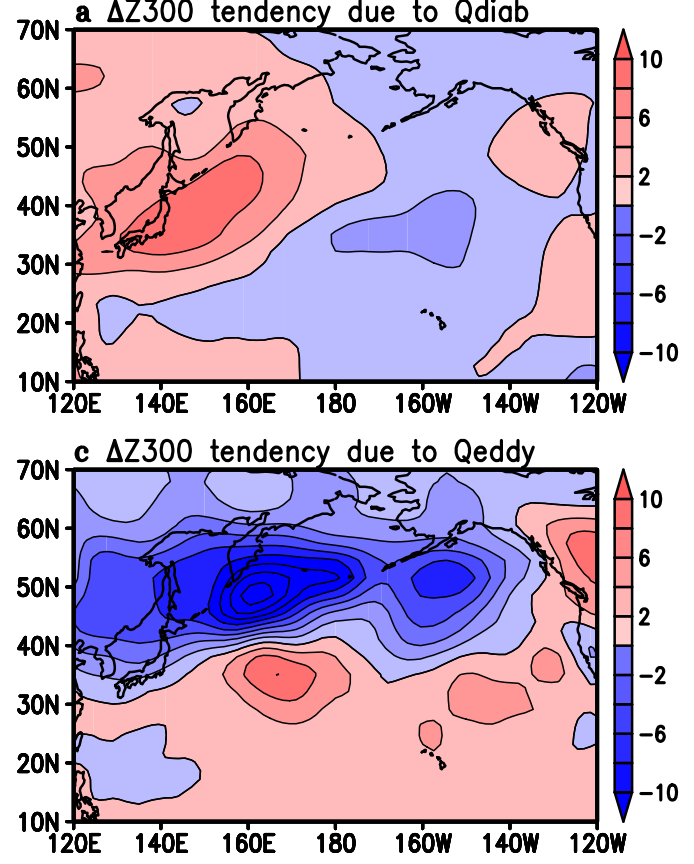

e $\Delta Z 300$ tendency due to Feddy

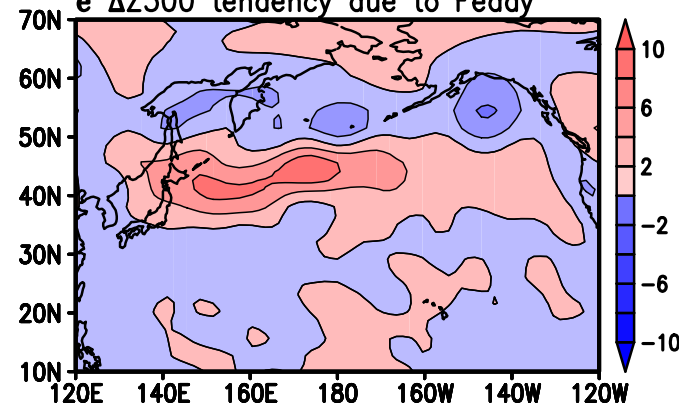

b $\Delta$ Z1000 tendency due to Qdiab

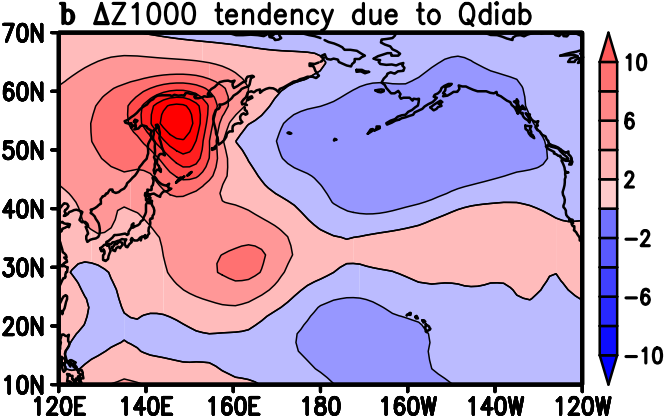

d $\Delta$ Z1000 tendency due to Qeddy

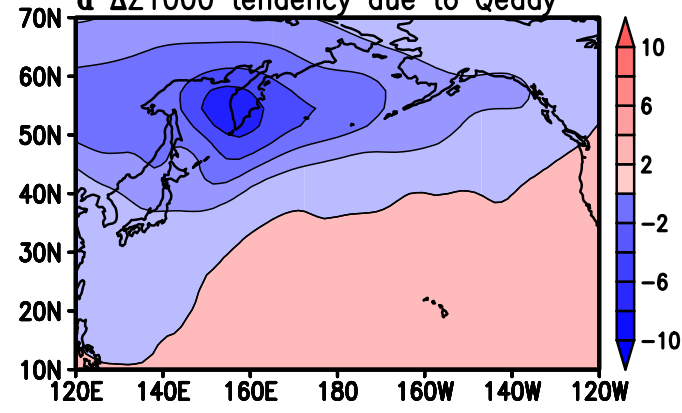

f $\Delta \mathrm{Z} 1000$ tendency due to Feddy

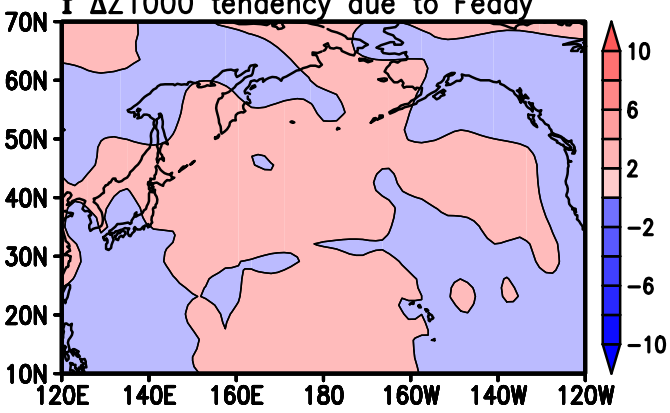

FIG. 8. Diabatic heating-induced geopotential height tendency anomaly ( $\mathrm{m} \mathrm{day}^{-1}$ ) at (a) 300 and (b) $1000 \mathrm{hPa}$. Similar panels are drawn for tendency anomaly due to (c),(d) eddy heat flux convergence and (e),(f) eddy vorticity flux convergence.

condensational heating released by the increased precipitation of baiu/mei-yu front (see Figs. 6 and 7a). Strong positive PV forcing due to eddy heat flux elongated zonally over the latitude band of the Okhotsk Sea (Fig. 7c). This forcing is mainly in upper tropospheric levels (Fig. 7d). PV forcing anomaly due to eddy vorticity flux behaves somewhat like that of eddy heat flux, but it is not so dominant (Figs. 7e,f).

Geopotential tendencies due to those forcing terms give clear aspects. The diabatic cooling induces intensification of the surface level Okhotsk high more dominantly than the upper level (Figs. 8a,b). On the other hands, the eddy forcing dominantly induces zonally elongated cyclonic anomaly in the upper level. The leading forcing is the eddy heat flux convergence (Figs. 8c,d), and the eddy vorticity flux convergence is the secondary (Figs. 8e,f). The eddy vorticity mainly induces the zonal elongation of an anticyclonic circulation, corresponding to the North Pacific subtropical high (Fig. 8e). Both eddy fluxes thus induce a north-south dipole pattern over western North Pacific in the upper level (Figs. 8c,e). In summary, the diabatic process plays a role in the west-side baroclinic structure over the Okhotsk region. The east-side geopotential anomalies are mainly from transient eddy forcing, which plays a role in the barotropic structure. These geopotential tendency anomalies

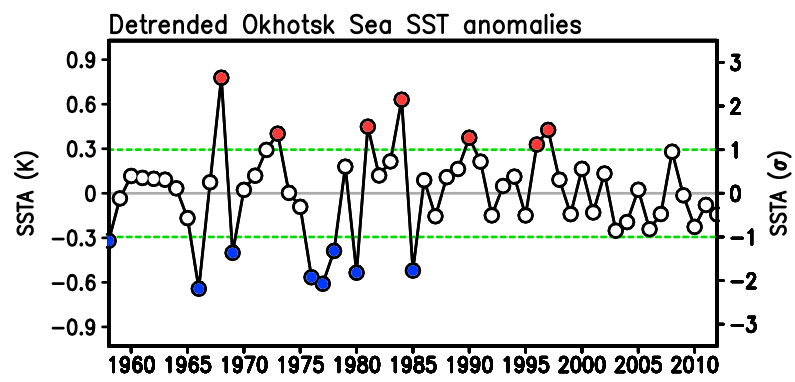

FIG. 9. Time series of interannual variation of May-June SST $\left({ }^{\circ} \mathrm{C}\right)$ averaged over the Okhotsk Sea. Linear trend component from 1958 to 2012 was removed. Filled red and blue circles indicate hot and cold years, respectively. 

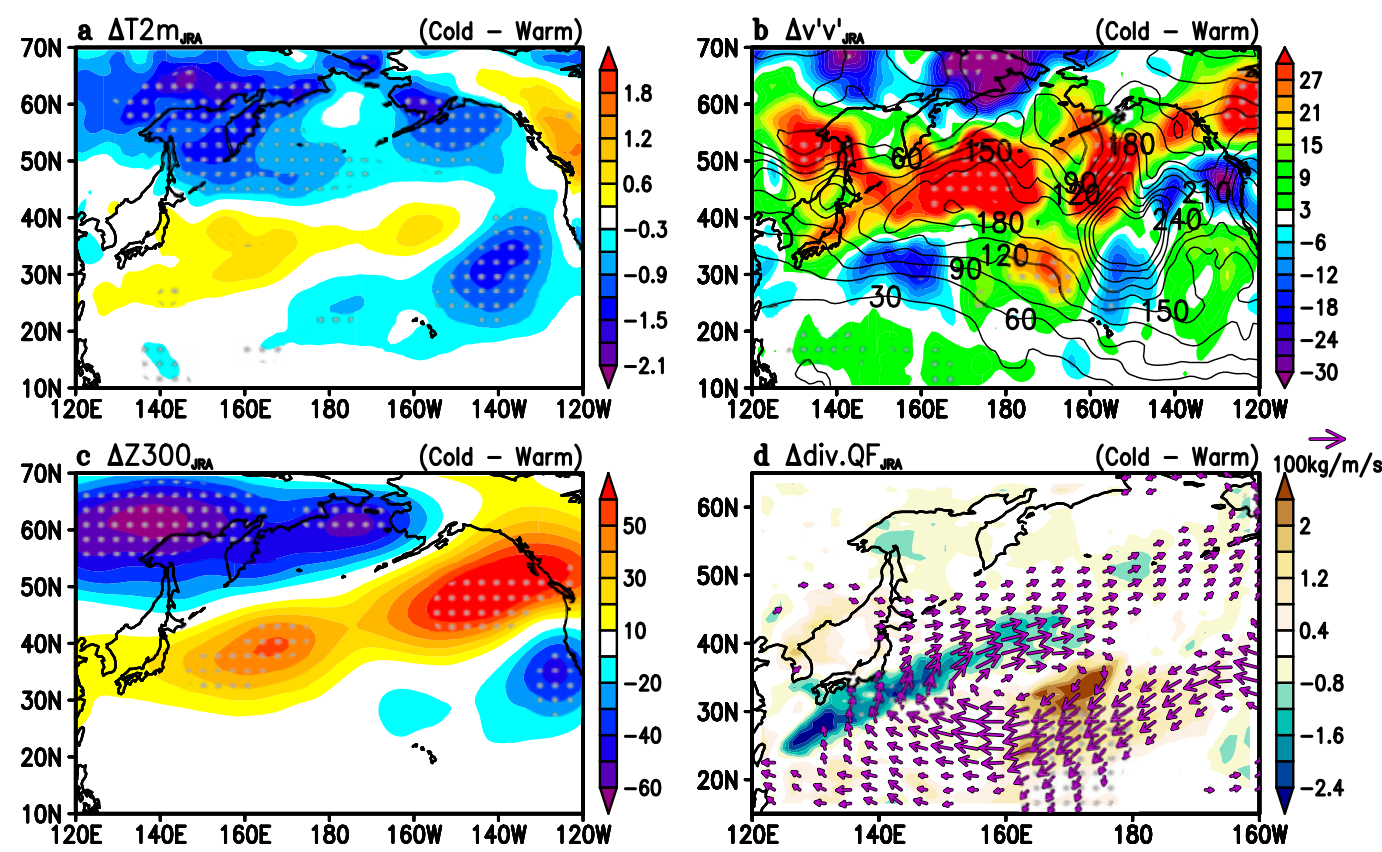

FIG. 10. Difference in May-June mean (a) temperature at 2-m height (K), (b) storm-track intensity at $300 \mathrm{hPa}$ $\left(\mathrm{m}^{2} \mathrm{~s}^{-2}\right)$, (c) geopotential height at $300 \mathrm{hPa}(\mathrm{m})$, and (d) moisture flux divergence $\left(\mathrm{mm} \mathrm{day}^{-1}\right)$ between cold years and hot years (cold years minus hot years). Contours in (b) indicate climatological mean of the storm-track intensity. Hatching indicates significance level above $90 \%$ based on a $t$ test. Arrows in (d) indicate differences in moisture flux, with an arrow length corresponding to $100 \mathrm{~kg} \mathrm{~m}^{-1} \mathrm{~s}^{-1}$ shown to the right of the panel.

diagnosed by QGPV well correspond to the geopotential highlow dipole pattern of the AGCM in the upper (Fig. 5a) and nearsurface (Fig. 5b) levels as well as the contrast between the west and east sides (Figs. 3a,b).

The diabatic heating by the increased precipitation of baiu/mei-yu front has an additional influence on westward extension of the subtropical high (see Figs. 8a,b). This implies that baiu/mei-yu front that is strengthened by the westward extension of the subtropical high further promotes its westward elongation and baiu precipitation, i.e., positive feedback.

\section{c. Supportive observational evidence}

In the previous section we demonstrated the ways in which the presence of the cold Okhotsk Sea affeccts climatological atmospheric factors through an ideal numerical experiment. In this section, we explore the supportive evidence from JRA-55 reanalysis data through examination of the interannual variation of SST in the Okhotsk Sea and its relevance to the atmospheric circulation changes shown in the numerical experiment. The warm/cold SST corresponds to the LAND/ CTL runs, respectively. Because even in the warm SST condition, the lower boundary is still ocean, not soil, it should be noted that the atmospheric fields in the warm SST do not completely represent the LAND run.

First, to make a time series dataset, we took the May-June averaged SST in the Okhotsk Sea with linear trend components removed for 1958 to 2012 (Fig. 9). For comparison with the ideal AGCM results, we performed composite analysis of cold years minus hot years based on $\pm 1 \sigma$ (std dev) of the SST time series. Note that a SST correlation map with the Okhotsk SST time series did not have any large-scale significant areas except for the Okhotsk area itself and its surrounds (figures not shown). We can thus confirm that observational composite analyses can derive signatures of Okhotsk SST influence, not by remote SST influences such as ENSO.

Figure 10a shows differences in temperature at $2 \mathrm{~m}$ between cold and hot years. Strong negative anomalies were seen around the Okhotsk Sea. Such cold anomalies cause intensification of baroclinicity in a manner similar to the AGCM results

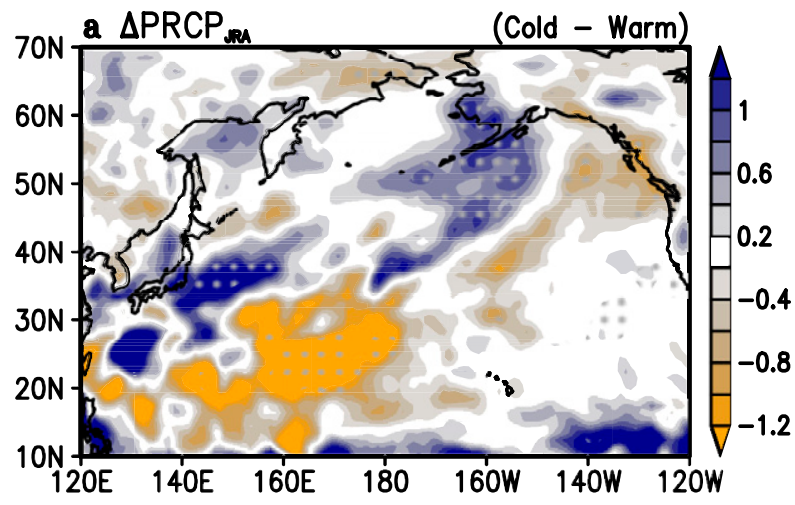

FIG. 11. Difference in May-June mean precipitation $\left(\mathrm{mm} \mathrm{day}^{-1}\right)$ between cold years and hot years (cold years minus hot years). Hatching indicates significance level above $90 \%$ based on a $t$ test. 
a

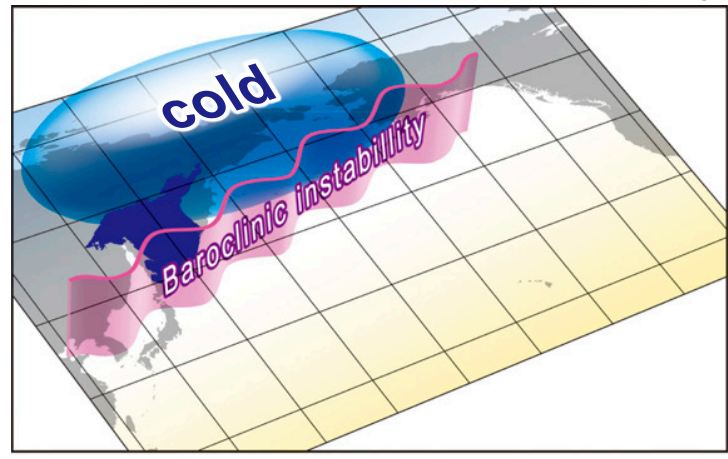

b
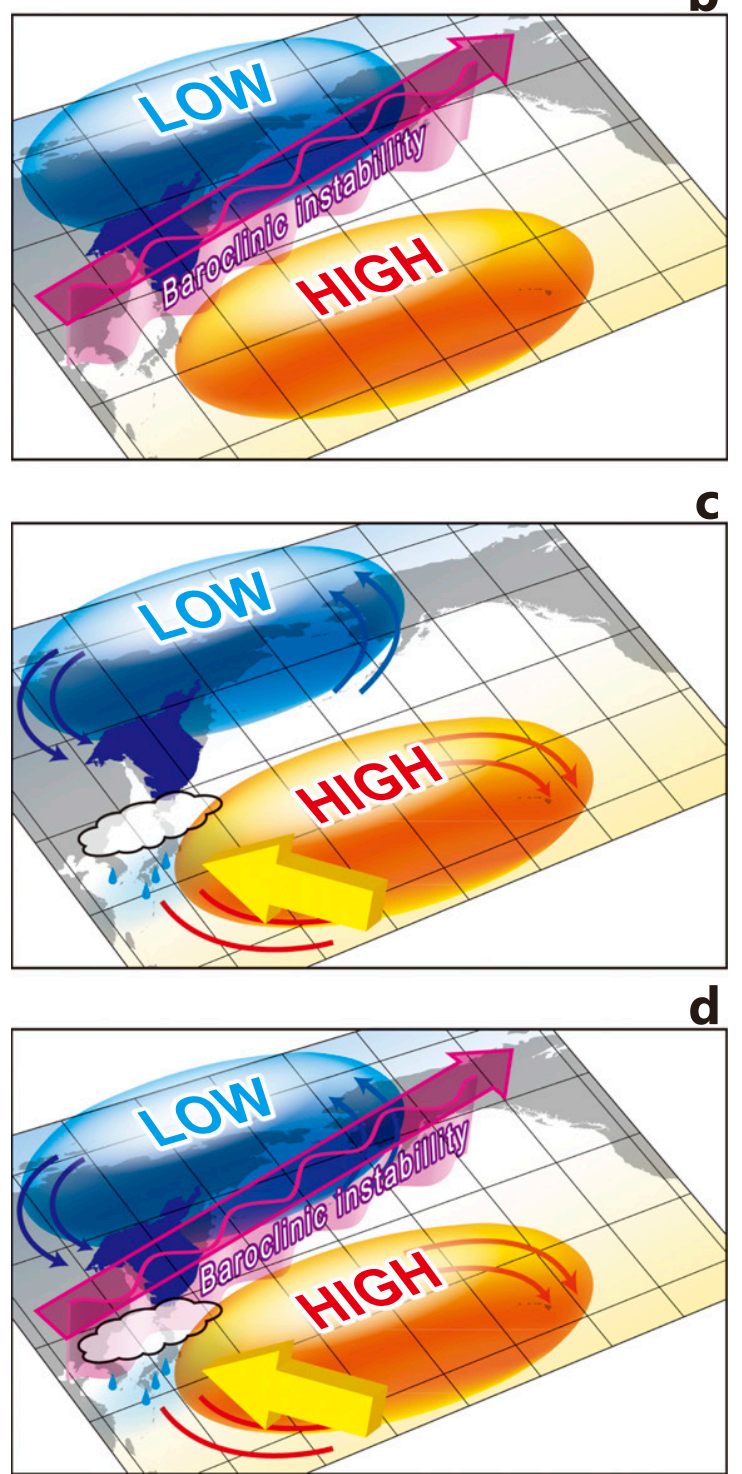

FIG. 12. Schematics showing the influence of the existence of the cold Okhotsk Sea with strengthening baiu rainfall. (a) The Okhotsk Sea locally forces the formation of cold air above and strengthens the Okhotsk high. Cold air extends to the middle troposphere and strengthens the temperature gradient between the and, thus, more active synoptic disturbances appear from south of the Okhotsk Sea to downstream of the Okhotsk (Fig. 10b). This anomalous storm-track activity is roughly similar to the AGCM results, although its statistical significance is not as high. As was the case for the simulation results, the anomalous eddy activity and its feedback to the mean flow, a meridional dipole pattern of geopotential height anomalies is seen as regions of negative anomalies over the Okhotsk Sea and positive anomalies over the northwestern Pacific (Fig. 10c). As these steady state circulation anomalies in association with cold SST anomalies in the Okhotsk Sea are roughly in accordance with the AGCM results, the signature of the effects of the existence of the Okhotsk Sea can be seen in the real world on an interannual time scale. Along the edge of anticyclonic anomalies, moisture transport from the Pacific to Japan increases as well (Fig. 10d), resulting in an increase in baiu-precipitation over Japan (Fig. 11).

These observation-based results serve as supportive evidence for the ideal AGCM results that the baiu-precipitation increased with the strengthened North Pacific subtropical high due to the presence of the Okhotsk Sea. Note that statistically significant differences were not as high in the observations, whereas amplitudes were larger in the observations than in the AGCM. This suggests that in the real world the atmospheric variations are largely affected by various forcing factors from the other subsystems along with the Okhotsk-Pacific linkage.

\section{Conclusions}

We performed an ideal numerical experiment using an AGCM under two conditions: a CTL run, in which climatological mean annual-cycle SST and sea ice were used as the boundary condition; and a LAND run, in which the model surface boundary over the Okhotsk Sea was changed from ocean to continental land. We compared these two runs to examine the influence of the presence of the Okhotsk Sea on climatological atmospheric circulations in the baiu/mei-yu season. The major difference in these conditions is heat capacity. In the summer season, the lower layer of the atmosphere around the Okhotsk Sea is cooler because of its large heat capacity compared to the continental conditions. Therefore, the Okhotsk Sea serves as strong cold source in the CTL run (i.e., real world). As the atmospheric circulation anomalies respond to this coldness, strengthening of the North Pacific subtropical high appears, which results in an increase in baiu-precipitation

$\longleftarrow$

midlatitudes and high latitudes. The temperature gradient enhances the baroclinic instability and thus forms a storm track extending eastward from around Japan to western North America. (b) Transient eddy heat and momentum transports associated with this storm track forces acceleration of the westerly jet stream, which strengthens an anomalous anticyclonic circulation to its south corresponding to the North Pacific subtropical high. (c) Along the western edge of the strengthened Pacific high, moisture is transported from the Pacific Ocean to Japan, resulting in an increase in the stationary baiu precipitation. (d) All of the processes combined. 
over Japan. Through interpretation of simulation results and its consistency with other observational results, we here propose a possible mechanism for the remote impact of the Okhotsk Sea (Fig. 12).

The presence of the Okhotsk Sea locally forces formation of significant strong cold temperature anomalies (Fig. 2c), which strengthens the Okhotsk high (Fig. 5b). These cold temperature anomalies extend to the middle layer in the troposphere, which strengthens the temperature gradient between the midlatitudes and high latitudes (Fig. 3). Anomalously strong meridional temperature gradient enhances the baroclinic instability, and thus forms a storm track extending eastward from around Japan to western North America (Figs. 4a,b). Transient eddy heat and momentum transports associated with this storm-track forcing accelerate the westerly jet stream along to this latitude band (Fig. 4c). The eddy forcing further induces an anomalous anticyclonic circulation to its south, corresponding to the North Pacific subtropical high (Figs. 5a,b). Along the western edge of the strengthened Pacific high, moisture is transported from the Pacific Ocean to Japan (Fig. 5c), resulting in an increase of stationary baiu-precipitation (Fig. 6).

As discussed in section 3, because the baiu-precipitation band appears in both the CLT and LAND runs, we speculate that the Okhotsk Sea is not necessarily required for forming the climatology of the baiu-precipitation. However, these model results indicate that baiu-precipitation and the associated North Pacific subtropical high would be significantly weakened without the local coldness of the Okhotsk Sea. These findings suggest that the present-day cold Okhotsk Sea plays a role in changing the midlatitude atmospheric circulation and increasing the baiu-precipitation. Climatologically, the ridge of the subtropical high extends westward (See contours in Fig. 5b). This westward extension can be partially caused by the cold Okhotsk Sea. These model results are well supported by reanalysis data based on the difference between cold and hot years of SST over the Okhotsk Sea. Thus, we consider that our simulation results are likely robust even though the experimental design includes an unrealistic condition.

Although July is still an active month of baiu, we have not shown Okhotsk influence in July. The Okhotsk influence in July is basically similar to that in May and June, but its amplitude is weaker than in May and June. We consider following reasons. Climatological meridional temperature gradient over the North Pacific is weaker in July than in early summer. Westerly jet stream and associated storm-track activity are also weak in July. The westerlies also shift northward in July. These climatological seasonal transitions are less favorable to the Okhotsk-induced linkage shown in this study. The weak signature in July is therefore consistent to the mechanism that the present study has shown.

In conclusion, we confirmed the role of the cold Okhotsk Sea in strengthening the North Pacific subtropical high and increasing baiu-precipitation through activation of the eddy feedback to mean flow. These findings implied that if the speed of increasing the Okhotsk SST due to global warming is slower than for the surrounding western North Pacific Ocean, the baiu-precipitation band will be strengthened. This perspective is very likely because the sea ice and oceanic tidal mixing in the
Okhotsk Sea would cause the warming to slow compared to the surrounding ocean. The Okhotsk SST was lower than normal in the summer of 2018 when an unprecedented catastrophic baiu event, "the heavy rain event of July 2018," happened in Japan. That summer had the hottest temperatures in midlatitudes in the Northern Hemisphere in the historical record (e.g., Shimpo et al. 2019). The large temperature contrast between the Okhotsk and the surrounding areas might contribute positively to these rain events to some extent. As this is beyond the scope of this study, this topic should be examined in the future.

Acknowledgments. YT, TN, and KY were supported by ArCS and ArCS-2 projects (JPMXD1300000000 and JPMXD1420318865) and Belmont Forum InterDec Project. YT was supported by the Ministry of Education, Culture, Sports, Science and Technology through Grants-in-Aid for Scientific Research (Grants 16 K13880, 17H02958, 17H01156, $17 \mathrm{~K} 01223$ ，19H05698，19H05695，19H05668，20 K12197, and 20H04306). We thank anonymous reviewers for their valuable comments and suggestions that improved the quality of the paper. We extend grateful thanks to K. K. Komatsu and Y. Ando; their enormous support and insightful comments were invaluable during the course of this study.

Data availability statement. The JRA-55 reanalysis data and HADISST data used during this study are openly available. They were downloaded from websites https://jra.kishou.go.jp/ JRA-55/ and https://www.metoffice.gov.uk/hadobs/hadisst, respectively. The AGCM simulation data used in this study are available from the corresponding author upon reasonable request.

\section{REFERENCES}

Cabinet Office, Japan, 2019: Report on damages by the heavy rain event of July 2018 (in Japanese). Cabinet Office, Japan, 204 pp., http://www.bousai.go.jp/updates/h30typhoon7/pdf/310109_ 1700_h30typhoon7_01.pdf.

Eady, E. T., 1949: Long waves and cyclone waves. Tellus, 1, 33-52, https://doi.org/10.3402/tellusa.v1i3.8507.

Enomoto, T., A. Kuwano-Yoshida, N. Komori, and W. Ohfuchi, 2008: Description of AFES 2: Improvements for high-resolution and coupled simulations. High Resolution Numerical Modelling of the Atmosphere and Ocean, K. Hamilton and W. Ohfuchi, Eds., Springer, 77-97.

Fang, J., and X.-Q. Yang, 2016: Structure and dynamics of decadal anomalies in the wintertime midlatidude North Pacific oceanatmosphere system. Climate Dyn., 47, 1989-2007, https:// doi.org/10.1007/s00382-015-2946-x.

Harada, Y., and Coauthors, 2016: The JRA-55 reanalysis: Representation of atmospheric circulation and climate variability. J. Meteor. Soc. Japan, 94, 269-302, https://doi.org/10.2151/jmsj.2016-015.

Honda, M., K. Yamazaki, Y. Tachibana, and K. Takeuchi, 1996: Influence of Okhotsk sea-ice extent on atmospheric circulation. Geophys. Res. Lett., 23, 3595-3598, https://doi.org/10.1029/ 96GL03474.

- — - H. Nakamura, and K. Takeuchi, 1999: Dynamic and thermodynamic characteristics of atmospheric response to anomalous sea-ice extent in the Sea of Okhotsk. J. Climate, 12, 3347-3358, https://doi.org/10.1175/1520-0442(1999)012<3347: DATCOA $>2.0 . \mathrm{CO} ; 2$. 
Hoskins, B. J., I. N. James, and G. H. White, 1983: The shape, propagation, and mean-flow interaction of large-scale weather systems. J. Atmos. Sci., 40, 1595-1612, https://doi.org/10.1175/ 1520-0469(1983)040<1595:TSPAMF $>2.0 . \mathrm{CO} ; 2$.

Hurrell, J. W., J. J. Hack, D. Shea, J. M. Caron, and J. Rosinski, 2008: A new sea surface temperature and sea ice boundary dataset for the Community Atmosphere Model. J. Climate, 21, 5145-5153, https://doi.org/10.1175/2008JCLI2292.1.

Kanno, H., 2013: Strongly negative correlation between monthly mean temperatures in April and August since 1998 in northern Japan. J. Meteor. Soc. Japan, 91, 355-373, https://doi.org/ 10.2151/jmsj.2013-308.

Kitoh, A., 2004: Effects of mountain uplift on East Asian summer monsoon climate investigated by a coupled atmosphereocean GCM. J. Climate, 17, 783-802, https://doi.org/10.1175/ 1520-0442(2004)017<0783:EOMUOE > 2.0.CO;2.

Koseki, S., T. Nakamura, H. Mitsudera, and Y. Wang, 2012: Modeling low-level clouds over the Okhotsk Sea in summer: Cloud formation and its effects on the Okhotsk high. J. Geophys. Res., 117, D05208, https://doi.org/10.1029/ 2011JD016462.

Kuwano-Yoshida, A., T. Enomoto, and W. Ohfuchi, 2010: An improved PDF cloud scheme for climate simulations. Quart. J. Roy. Meteor. Soc., 136, 1583-1597, https://doi.org/10.1002/ qj.660.

Lau, N.-C., and M. J. Nath, 1991: Variability of the baroclinic and barotropic transient eddy forcing associated with monthly changes in the midlatitude storm tracks. J. Atmos. Sci., 48, 2589-2613, https://doi.org/10.1175/1520-0469(1991)048<2589: VOTBAB $>2.0 . \mathrm{CO} ; 2$.

Moteki, Q., 2019: Role of Typhoon Prapiroon (Typhoon No. 7) on the formation process of the Baiu front inducing heavy rain in July 2018 in western Japan. SOLA, 15A, 37-42, https://doi.org/ 10.2151/sola.15A-007.

Nakamura, H., and T. Fukamachi, 2004: Evolution and dynamics of summertime blocking over the Far East and the associated surface Okhotsk high. Quart. J. Roy. Meteor. Soc., 130, 12131233, https://doi.org/10.1256/qj.03.101.

Nakamura, T., T. Awaji, T. Hatayama, K. Akitomo, and T. Takizawa, 2000: Tidal exchange through the Kuril Straits. J. Phys. Oceanogr., 30, 1622-1644, https://doi.org/ 10.1175/1520-0485(2000)030<1622:TETTKS > 2.0.CO;2.

_-, K. Yamazaki, K. Iwamoto, M. Honda, Y. Miyoshi, Y. Ogawa, and J. Ukita, 2015: A negative phase shift of the winter $\mathrm{AO} / \mathrm{NAO}$ due to the recent Arctic sea-ice reduction in late autumn. J. Geophys. Res., 120, 3209-3227, https:// doi.org/10.1002/2014JD022848.

$\_, \ldots$, T. Sato, and J. Ukita, 2019: Memory effects of Eurasian land processes cause enhanced cooling in response to sea ice loss. Nat. Commun., 10, 5111, https://doi.org/10.1038/s41467019-13124-2.

Ninomiya, K., and H. Mizuno, 1985: Anomalously cold spell in summer over northeastern Japan caused by northeasterly wind from polar maritime air-mass. Part 2. Structure of the north-easterly flow from polar maritime airmass. J. Meteor. Soc. Japan, 63, 859-871, https://doi.org/10.2151/jmsj1965.63.5_ 859.

—_, and H. Muraki, 1986: Large-scale circulations over East Asia during Baiu period of 1979. J. Meteor. Soc. Japan, 64, 409-429, https://doi.org/10.2151/jmsj1965.64.3_409.

—_, and Y. Shibagaki, 2007: Multi-scale features of the MeiyuBaiu front and associated precipitation systems. J. Meteor.
Soc. Japan, 85B, 103-122, https://doi.org/10.2151/jmsj. 85B.103.

Nishikawa, H., Y. Tachibana, and Y. Udagawa, 2014: Radiosonde observational evidence of the impact of an extremely cold SST spot on a mesoscale anticyclone. J. Geophys. Res., 119, 91839195, https://doi.org/10.1002/2014JD021538.

Ogi, M., Y. Tachibana, and K. Yamazaki, 2004: The connectivity of the winter North Atlantic Oscillation (NAO) and the summer Okhotsk high. J. Meteor. Soc. Japan, 82, 905-913, https:// doi.org/10.2151/jmsj.2004.905.

Ohfuchi, W., and Coauthors, 2004: 10-km mesh meso-scale resolving simulations of the global atmosphere on the Earth Simulator-Preliminary outcomes of AFES (AGCM for the Earth Simulator). J. Earth Simul., 1, 8-34.

—, H. Sasaki, Y. Masumoto, and H. Nakamura, 2007: "Virtual" atmospheric and oceanic circulation in the Earth Simulator. Bull. Amer. Meteor. Soc., 88, 861-866, https://doi.org/10.1175/ BAMS-88-6-861.

Onogi, K., and Coauthors, 2007: The JRA-25 Reanalysis. J. Meteor. Soc. Japan, 85, 369-432, https://doi.org/10.2151/jmsj.85.369.

Rayner, N. A., D. E. Parker, E. B. Horton, C. K. Folland, L. V. Alexander, D. P. Rowell, E. C. Kent, and A. Kaplan, 2003: Global analyses of sea surface temperature, sea ice and night marine air temperature since the late nineteenth century. J. Geophys. Res., 108, 4407, https://doi.org/10. 1029/2002JD002670.

Sampe, T., and S.-P. Xie, 2010: Large-scale dynamics of the meiyu-baiu rainband: Environmental forcing by the westerly jet. J. Climate, 23, 113-134, https://doi.org/10.1175/ 2009JCLI3128.1.

Shimpo, A., and Coauthors, 2019: Primary factors behind the heavy rain event of July 2018 and the subsequent heat wave in Japan. SOLA, 15A, 13-18, https://doi.org/10.2151/sola.15A-003.

Tachibana, Y., T. Iwamoto, M. Ogi, and Y. Watanabe, 2004: Abnormal meridional temperature gradient and its relation to the Okhotsk high. J. Meteor. Soc. Japan, 82, 1399-1415, https:// doi.org/10.2151/jmsj.2004.1399.

—, K. Iwamoto, H. Ogawa, M. Shiohara, K. Takeuchi, and M. Wakatsuchi, 2008: Observational study on atmospheric and oceanic boundary-layer structures accompanying the Okhotsk anticyclone under fog and non-fog conditions. J. Meteor. Soc. Japan, 86, 753-771, https://doi.org/10.2151/jmsj.86.753.

Tao, L., X.-Q. Yang, J. Fang, and X. Sun, 2020: PDO-related wintertime atmospheric anomalies over the midlatitude North Pacific: Local versus remote SST forcing. J. Climate, 33, 69897010, https://doi.org/10.1175/JCLI-D-19-0143.1.

Tokinaga, H., and S.-P. Xie, 2009: Ocean tidal cooling effect on summer sea fog over the Okhotsk Sea. J. Geophys. Res., 114, D14102, https://doi.org/10.1029/2008JD011477.

Wang, L., X.-Q. Yang, D. Yang, Q. Xie, J. Fang, and X. Sun, 2017: Two typical modes in the variabilities of wintertime North Pacific basin-scale oceanic fronts and associated atmospheric eddy-driven jet. Atmos. Sci. Lett., 18, 373-380, https://doi.org/ 10.1002/asl.766.

Wang, Y., 1992: Effects of blocking anticyclones in Eurasia in the rainy season (Meiyu/Baiu Season). J. Meteor. Soc. Japan, 70, 929-951, https://doi.org/10.2151/jmsj1965.70.5_929.

Yamamoto, K., Y. Tachibana, M. Honda, and J. Ukita, 2006: Intraseasonal relationship between the Northern Hemisphere sea ice variability and the North Atlantic Oscillation. Geophys. Res. Lett., 33, L14711, https://doi.org/10.1029/2006GL026286. 